Original Research Paper

\title{
Psychological Effects of Youth Unemployment in Ghana
}

\author{
Christopher M. Amissah and Kingsley Nyarko \\ Department of Psychology, University of Ghana, Legon, Accra, Ghana
}

\author{
Article history \\ Received: 30-07-2016 \\ Revised: 16-01-2017 \\ Accepted: 08-03-2017 \\ Corresponding Author: \\ Christopher M. Amissah \\ Department of Psychology, \\ University of Ghana, Legon, \\ Accra, Ghana \\ Email: chrismartinamissah@gmail.com
}

\begin{abstract}
This study investigated the psychological effects of youth unemployment in Ghana. Youths within the ages of 18 and 35 years in the Greater Accra Region of Ghana constituted the research population. A sample of 362 youths, comprising both the employed $(n=172)$ and the unemployed $(n=190)$, were purposively selected. The employed youths served as a control group for comparative analyses. The cross-sectional survey design was adopted. The Hopelessness Depression Symptom Questionnaire (HDSQ), the Automatic Thoughts Questionnaire (ATQ), the Rosenberg's Self-esteem Scale and the Suicidal Behaviors Questionnaire-Revised (SBQ-R) were used to assess psychological health (i.e., depression, cognitive distortions, self-esteem and suicidality) of the respondents. The Pearson $r$ test, the Linear Regression test and the Multivariate Analysis of Variance (MANOVA) test were used to analyze the data. The findings showed poorer psychological health among unemployed youths than employed youths. Duration of unemployment significantly predicted poorer psychological health among the youths. The findings and their implications are discussed with references to the existing literature and theories.
\end{abstract}

Keywords: Unemployment, Depression, Cognitive Distortions, Self-Esteem, Suicidality

\section{Introduction}

Ghana's present population consists of about $57 \%$ youths (GSS, 2012). This means Ghana has a youthful population structure. Over the past fifty years, the number of youths in the total Ghanaian population has increased from 1.1 million in 1960 to 2.3 million in 1984, to 3.5 million in 2000 (Amankrah, 2005) and to 13.7 million in 2010 (GSS, 2012). Youths constitute approximately $22.6 \%$ of the economically active population (GSS, 2012). The proportion of the youth in the Ghanaian population corresponds with their share of the unemployment rate in Ghana. Nearly $60 \%$ of the unemployed in Ghana are in their youthful age (Amankrah, 2005). This makes Ghana's youth unemployment rate one of the highest worldwide. Youth unemployment in Ghana is concentrated largely in urban cities. In Accra, the nation's capital, unemployment rate is about $30.8 \%$, compared to $11.5 \%$ in the rural settings and 23.5\% in other urban cities (Amankrah, 2005).

Youth unemployment has become an issue in public discussions in the Ghanaian society. Unemployment is a situation whereby individuals are unable to find a paid job despite their readiness and willingness to work (Fajana, 2000). According to the International Labour Organization (ILO, 1982), unemployment occurs when individuals without paid job actively seek to find one. Unemployment has numerous negative consequences on those who are affected (Lorenzini and Giugni, 2010). A deprivation of paid job involves the risk of isolation and social exclusion (Paugam, 2004) as well as deteriorating effects on personal life and well-being (Jahoda et al., 1933). This is even truer with a prolonged unemployment. Evidence suggests that exposure to negative life events, such as unemployment, impairs an individual's psychological well-being (Erikson, 1968; Jahoda, 1979; 1981; 1982; Seligman, 1975) and may lead to suicidal thoughts (Osafo et al., 2011).

Dooley et al. (2000) opposed the idea of comparing the unemployed with the employed due to differences in the quality of paid jobs. They argued that poorer quality jobs have a greater tendency to impair an individual's mental health compared with better quality jobs. Thus, simply comparing the employed with the unemployed is likely to underestimate the impact of losing a good job. To address this problem, Dooley et al. (2000) created a 
new category and termed it "inadequate employment". This included involuntary part-time work and low-wage work. They observed that both the unemployed and the inadequately employed were significantly more depressed than those who were adequately employed.

Although the consequences of unemployment are multifaceted (social, economic, political and psychological), earlier researchers in Ghana (e.g., ISSER, 2007; Yarquah and Baafi-Frimpong, 2012) have ignored the psychological dimension which may be as devastating as the social, economic and political consequences. Studies on the relationship between unemployment and mental health indicate that unemployment adversely affects mental health and reemployment improves it (Ezzy, 1993; Feather, 1990; Murphy and Athanasou, 1999; Winefield, 1995). The classical study of Jahoda et al. (1933) shows that prolonged unemployment negatively affects individuals' entire life. This suggests a causal relationship between unemployment and mental health; what is termed causation hypothesis.

A number of studies report a significant association between unemployment and poor mental and physical health, as well as unfavorable health habits (McKee-Ryan et al., 2005; Cohen et al., 2007; Paul, 2005; Paul and Moser, 2009). However, Schaufeli (1997) noted that the strength of the association is rather weak. Approximately, unemployment accounts for only 10 to $15 \%$ of the variance in psychological distress (Fryer and Payne, 1986). Second, Schaufeli (1997) argued that though unemployment causes psychological distress, high levels of distress may as well cause prolonged unemployment, implying that the relationship may rather be mutual. Winefield and Tiggemann (1985) reported that poor self-esteem and depressed mood were both antecedents and effects of unemployment. Thus, poor mental health may cause unemployment; a situation termed as reversed causation or selection hypothesis. Whilst the causation hypothesis deals with the negative impact of unemployment on mental health, the selection hypothesis refers to the factors that predict occupational success. The former is the focus of the present study.

\section{Unemployment and Social Vices}

The lack of employment opportunities in poor economies is known to have a lot of social implications. Youth unemployment promotes rural-urban migration and a wide range of social vices. It has been reported that the lack of jobs and the fear of a bleak future contribute considerably to crime and deviant behaviours among the youths (Sommers, 2003). The increase in crime, drug addiction and prostitution are among the negative social consequences of youth unemployment. According to the ILO (2005), in Africa, unemployment has led many girls and young women to become social sex workers.
Yarquah and Baafi-Frimpong (2012) examined the social cost of educated youth unemployment in Ghana and reported that educated youth unemployment led to streetism and its attended social vices such as stealing, drug abuse and prostitution. In their investigation of the link between unemployment and crime, Carmichael and Ward (2001) revealed that youth unemployment and the different types of crime such as theft, burglary, fraud and forgery in England and Wales are positively correlated.

\section{Unemployment and Suicide Behavior}

Suicidality may be counted among the negative consequences of unemployment. Many of the existing studies on the correlates of suicide risk identify a variety of situational factors (Peña et al., 2008; Rew et al., 2001; Wadsworth and Kubrin, 2007). Negative life events exceptionally contribute to suicide risk (Chang et al., 2010). Among these negative life events or situational factors is unemployment. According to World Health Organization (WHO, 2000), there are fairly strong but complex relationship between unemployment and suicide. In their examination of the association between exposure to unemployment and suicidal behaviours, Fergusson et al. (2007) observed among New Zealand youths that, at all ages, prolonged unemployment predicted increased risks of suicidal ideation and suicide attempts. Córdoba-Doña et al. (2014) noted that the economic crisis in Europe led to a significant increase in suicide rates in many of the European countries. In Andalusia, the most populated region of Spain, Córdoba-Doña et al. (2014) discovered a significant increase in suicide attempt rates after the onset of the economic crisis. There was a significant association between suicide attempt rates and unemployment rates in men, accounting for nearly half of the cases in the early years of the crisis. Whilst women were impacted by the economic crisis, the increase in their suicide rates could not specifically be attributed to unemployment. The study of Córdoba-Doña et al. (2014) provides impetus for an investigation into suicide attempts in Ghana as an effect of the current crisis in the Ghanaian labour market, especially given that such effects differ crossculturally in nature and process.

\section{Unemployment and Mental Health}

Studies reveal that many unemployed youths feel marginalized, pessimistic and lacking in control over their lives. In a meta-analyses on the impact of unemployment on mental health, Paul and Moser (2009) noted that individuals who are unemployed show more distress than employed individuals. Compared to the employed, unemployed individuals had poorer subjective well-being, lower self-esteem and higher levels of depression, distress, anxiety and 
psychosomatic symptoms. Just as Córdoba-Doña et al. (2014) noted in relation to suicide rates, Paul and Moser (2009) also observed that the adverse impact of unemployment on mental health was greater in countries with weak unemployment protection systems, weak economic development and unequal income distributions. Reine et al. (2013) maintained that longterm youth unemployment could have various health implications in men and women. In a longitudinal study, Reine et al. (2013) observed a significant association between unemployment and suboptimal self-rated health among women and unemployment and high alcohol consumption among men.

Breslin and Mustard (2003) examined differences in mental health among younger and older adults with an extensive analysis of longitudinal data from the National Population Health Survey in Canada. They assessed both causation and selection effects of unemployment. Their analyses revealed that unemployment predicted a higher chance of mental distress for older adults within the ages of 31-55, but less likelihood for younger adults within the ages 1830. Their finding is in agreement with the observation of Clark and Oswald (1994) that the effect of unemployment on psychological distress is greatest for adults within the ages of 30-49.

The Organization for Economic Co-operation and Development (OECD, 2008) examined the impact of the labour market on mental health using longitudinal data obtained from Australia, Canada, Korea, Switzerland and the United Kingdom (U.K.). The findings showed that a movement from employment to unemployment was accompanied with a significant adverse effect on mental health, with men experiencing worse conditions of mental health than women. In Australia, Canada, Switzerland and the U.K., a change from employment to inactivity due to illness was accompanied with a greater increase in psychological distress. A movement from employment to unemployment equally had a significant negative impact on mental health. The OECD further discovered that that when the status of individuals changed from unemployment to employment, their mental health improved significantly with exceptions for women in Korea and Switzerland and men in Australia. Both men and women in Canada experienced significant gains in mental health with a change from unemployment to employment, with somewhat greater gains for men. Whilst duration of unemployment mattered, the impact differed across countries. In the U.K., a "habituation" effect occurred whereby psychological distress became greater at the early stages of unemployment and lesser at later stages. However, the "habituation" effect was not found in Australia. Rather, prolonged unemployment worsened mental health for Australian males.
Pharr et al. (2012) observed in their study that the unemployed had poorer perceived mental health profiles and poorer access to health care services than the employed. In addition, duration of unemployment was significant in predicting the severity of health outcomes. On the contrary, Winkelman and Winkelman (1998) observed that the size of the effect was unrelated to the duration of unemployment. However, their study is quite old and needs replication.

The reformulated learned helplessness theory of depression and the hopelessness theory of depression can best explain how unemployed youths tend to develop mental health problems. The reformulated learned helplessness model was formulated by Abramson et al. (1978) to explain affective, motivational and cognitive deficits in humans as a result of exposure to uncontrollable negative events. According to the model, a pessimistic attribution occurs when one attributes negative events to internal, stable and global causes. This kind of attribution results in a helpless reaction such as anxiety, hostility, passivity, sadness and low self-esteem (Peterson and Seligman, 1984). Although the reformulated learned helplessness model attempted to provide an explanation for human helplessness and depression, it could not provide an explicit theory of depression in itself. This led to its revision into the hopelessness model of depression by Abramson et al. (1989).

According to the hopelessness model of depression, people with maladaptive cognitive styles become susceptible to depression following adverse life events. This is because they tend to make negative interpretations of the events. The model postulates a subtype of depression - hopelessness depression - with a characteristic cause, symptom profile, course, treatment and prevention. The symptoms include insomnia, motivational deficit, sad affect, apathy, anergia, difficulty in concentration, psychomotor retardation, mood-exacerbated negative cognitions and suicidality. Although interpersonal dependency and low self-esteem are included in the clinical symptoms under specified conditions (Abramson et al., 1989), research suggests that low self-esteem may be best classified as a causal sequence (Metalsky et al., 1993; Roberts and Monroe, 1992). Moreover, interpersonal dependency may be a symptomatic feature of hopelessness depression (Metalsky and Joiner, 1997). Contemporary studies (Alloy et al., 2006; 2000) have focused on the tendency to make stable and global attributions referred to as negative cognitive style. Individuals with negative cognitive style have been found to be at greater risk for depression (Nyarko and Amissah, 2014).

Based on the theoretical explanations, the present study assesses how various psychological variables of mental health are affected by stressors associated with 
unemployment. Among these variables are depression, cognitive distortions, low self-esteem and suicidal ideation. The relationships among these variables and their link with stressful life events suggest that they can together act as likely consequences of unemployment. Unemployment, in this context, is conceptualized as a stressful life event for those who are affected.

Three factors from the general literature informed the conduct of the present study. First, findings on the psychological effects of unemployment have not been consistent across countries. For instance, it is known in the literature that the duration of unemployment matters, but the impact varies across countries (OECD, 2008). Therefore, one cannot simply assume that the psychological effects of unemployment, as documented in other countries, can be generalized in whole to unemployed youths in Ghana. In this regard, Winefield and Fryer (1996) suggested the need to consider historical and societal settings in the interpretation of empirical results on unemployment and mental health. This view is sustained by the observation of Paul and Moser (2009) regarding the adverse consequence of unemployment on mental health in different economies. Second, suicidal ideation has not prominently featured in the literature on the psychological effects of youth unemployment, though there are some indications from qualitative studies that suggest that suicidal ideation cannot be ruled out from the psychological effects of youth unemployment. The present study therefore seeks to expand the scope of research by investigating suicidal ideation as a negative consequence of unemployment in the Ghanaian society.

The final reason is the use of quantitative approach to establish suicidal ideation as an effect of youth unemployment in Ghana. Methodologically, most of the studies on suicide and suicidal ideation in Ghana have exclusively relied on qualitative design to identify unemployment as one of the risk factors for suicide (Adinkrah, 2014; Osafo et al., 2011; Knizek et al., 2010). Given the inherent limitations of qualitative studies, the present study was carried out as a sequel to these earlier qualitative studies with the objective of testing these earlier findings with quantitative data from a large sample. This will help to establish the validity of qualitative research findings and increase their utility/generalizability. Consequently, two hypotheses were formulated and tested in the present study. The first was that there will be poorer psychological health among unemployed youths than employed youths. The second was that that duration of unemployment will significantly predict poorer psychological health among the youths. Psychological health was defined in terms of depression, cognitive distortions, self-esteem and suicidality.

\section{Materials and Methods}

\section{Population/Sample}

Youths in the Greater Accra region of Ghana between the ages of 18 and 35 constituted the population for the research. The Greater Accra region is the most populous region for unemployed youths. It is the capital of Ghana and attracts most young people who are seeking greener pastures. The research population was sub-categorized into two: The employed and unemployed youths. Employed youths are youths who are actively engaged in paid jobs. Unemployed youths are youths who have not been in active employment for a period not less than one year. The population consisted of both males and females with varied characteristics. A total of 362 youths were sampled for the study. All respondents were selected from the Greater Accra Region. The sample consisted of $52.5 \%$ unemployed youths $(n=190)$ and $47.5 \%$ employed youths $(n=172)$ who served as control. The ages of the participants ranged from 18 to 35 years $(M=25.72, S D=4.60)$. In terms of gender composition, there were $51.9 \%$ females $(n=188)$ and $48.1 \%$ males $(n$ $=174)$. With regard to their marital status, $81.8 \%$ were single $(n=296), 15.5 \%$ were married $(n=56)$ and $2.8 \%$ were divorced $(n=10)$. Christians constituted $89.8 \%(n=$ 325), Muslims constituted 7.7\% $(n=28)$, Traditionalists constituted $1.1 \%(n=4)$ and those in other religions made up of $1.4 \%$ of the sample $(n=5)$. With regard to educational background, $50.3 \%$ of the respondents had tertiary education $(n=182), 36.7 \%$ had secondary education $(n=133), 10.5 \%$ had basic education $(n=38)$ and $2.5 \%$ had no formal education $(n=9)$.

\section{Sampling Techniques}

Purposive and snowball sampling techniques were used for the sample selection. The purposive sampling technique ensures that participants are selected based on specific characteristics or traits that best suit a study. Here, the researchers purposely searched out for youths who were either employed or unemployed. In order to reach the unemployed youths, the researcher adopted the snowball sampling technique. This technique requires a researcher to first identify one or two members of a group and then use them as informants to reach other members of the group. Since unemployed youths are likely to establish friendship among themselves (Russell, 1999), the researchers used unemployed friends to identify and select a significant number of unemployed youths. Thus, a significant number of unemployed youths was selected through the use of the snowball technique.

\section{Design}

The cross-sectional survey research design was used in this study. A survey research, according to Punch (2005), attempts to use questionnaires to survey 
individuals across a broad spectrum in a social research situation. The design is concerned with the relative accuracy with which an outcome variable is influenced by different situational and demographic factors. The cross-sectional survey design was appropriately chosen for the present study because questionnaires were used to collect data on the research variables from a crosssection of the research population at a single point in time. In addition, the design was deemed appropriate because the study involved respondents of different sex, age, employment status and socio-economic background.

\section{Measures}

Questionnaires were used as the instrument for data collection on the research variables. Each questionnaire had five sections. The first four sections comprised standardized scales that measured the key variables of the study. The last section of the questionnaire measured the demographic variables of the respondents such as gender, age, marital status, religious affiliation, educational background and employment status. Three types of employment status were measured in terms of respondents' self-ratings. Respondents were asked to indicate whether they are currently fully employed, somehow employed, or unemployed, depending on how they judge their own employment situation. Respondents who indicated somehow employed constituted the category of "inadequate employment". Respondents who indicated fully employed constituted the category of "adequate employment". Both categories constituted "employed youths" for the study. If unemployed, respondents were asked to indicate the number of years they have stayed unemployed. This provided the measure for "duration or length of unemployment." Details of the scales used in designing the questionnaire are provided below.

Hopelessness Depression Symptom Questionnaire (HDSQ; Metalsky and Joiner, 1997; $\alpha=0.93$ )

The HDSQ was designed to measure the symptoms of hopelessness depression. It is a 32-item self-report measure that allows investigators to examine individual and combined symptoms of hopelessness depression. There are a total of eight subscales and each measures a different symptom of hopelessness depression. Each symptom is measured by a cluster of four items. The alpha coefficients for each subscale in a sample of 435 were: (a) Motivational Deficit (retarded initiation of voluntary responses; alpha $=0.70$ ); (b) Dependency (alpha $=0.72)$; (c) Psychomotor Retardation (alpha = 0.74); (d) Anergia (alpha =0.86); (e) Apathy/Anhedonia (alpha $=0.75)$; (f) Insomnia (alpha $=0.81)$; (g) Difficulty in Concentration/Brooding (alpha $=0.80$ ); and (h) Suicidal ideation/impulses (alpha $=0.86$ ). The alpha coefficient for the full HDSQ was 0.93 (Metalsky and Joiner, 1997). The HDSQ was adapted for the study. The cluster of four items was modified into a single statement each and was scored on a 4-point Likert scale. Sampled items of the modified HDSQ are "I have stopped trying to get what I want," "My speech is slowed down," "I can concentrate as well as usual," and "I am having impulses to kill myself." The modified HDSQ was scored as strongly disagree $=1$ mark, disagree $=2$ marks, agree was assigned 3 marks and strongly agree $=3$ marks. The first 28 items were used to measure depression. The remaining 4 items of the scale (items 29-32) which originally measure suicidality were extracted and added to the Suicidal Behaviors Questionnaire-Revised (SBQ-R) to measure suicidality at the point of scoring in the present study. Total scores of the modified scale (all items inclusive) ranged from 32 (minimum) to 128 (maximum). Lower scores reflected lower level of hopelessness depression and higher scores reflected higher levels of hopelessness depression.

\section{The Suicidal Behaviors Questionnaire-Revised (SBQ-R; Osman et al., 2001; $\alpha=0.88$ )}

The SBQ-B assesses the history of suicide behaviors, suicidal ideation within the past year, frequency of suicidal ideation, previous suicide attempts and the likelihood of future attempts. Sampled items from the scale are "Have you ever thought about or attempted to kill yourself?" and "How likely is it that you will attempt suicide someday?" Higher risk of future suicidal behavior is associated with higher scores. A cut-off score of 7 has been shown to distinguish suicidal from nonsuicidal individuals (Osman et al., 2001). The reported reliability of this measure is 0.88 for adolescent inpatient samples and 0.87 for high school samples (Osman et al., 2001). Among adolescent inpatient sample, Osman et al. (2001) observed a Cronbach's alpha of 0.88 for the full scale. Inter-correlations among items ranged from 0.62 to 0.70 . Total score on the scale differentiated between suicidal and non-suicidal adolescents with an odds ratio of 2.19. They further observed a Cronbach's alpha of 0.87 among a high school sample with item intercorrelations ranging from 0.48 to 0.82 . The SBQ-R was scored on a frequency response scale. Responses ranged from never to very often. However, the pattern of responses was not consistent across all items. Total scores ranged from 4 (minimum) to 18 (maximum). Higher scores reflected higher suicidality and lower scores reflected lower suicidality. Items of the SBQ-R were added to the Suicidality subscale of the HDSQ. The merger of the two scales provided a measure for suicidality in the present study.

\section{Rosenberg's Self-Esteem Scale (Rosenberg, 1965; $\alpha$ $=0.86$ )}

The Rosenberg Self-esteem Scale measures individual's self-esteem. The scale is a 10 -item self- 
report scale designed to measure global self-esteem with a Cronbach alpha reliability range of 0.79 to 0.86 . Some items in the scale are "I feel that I have a number of good qualities," "I feel I do not have much to be proud of," and "At times I think I am no good at all." Responses are provided on a 4-point Likert scale ranging from "Strongly Agree" (with 4 marks), "Agree" (3 marks), "Disagree" (2 marks) and "Strongly Disagree" (1). Items $3,5,8,9$ and 10 are reverse scored in which a "Strongly Agree" response attracts 1 mark, "Agree" with 2 marks, "Disagree" with 3 marks and "Strongly Disagree" with 4 marks. Scores on the scale are continuous. Possible total scores per participant range from 10 (lowest self-esteem) to 40 (highest self-esteem).

\section{Automatic Thoughts Questionnaire (ATQ; Hollon and} Kendall, 1980; $\alpha=0.96$ )

The ATQ measures the frequency of automatic negative thoughts associated with depression. It identifies the covert self-statements usually reported by depressives as being representatives of their cognitions. The ATQ contains 30 items. Each item is a negative thought and the respondents are asked to rate the frequency with which they recall experiencing these thoughts during the previous week. Among the items of ATQ are "I'm no good," "I wish I were a better person" and "There must be something wrong with me." Frequency ratings are made on a five-point scale from 1 (not at all) to 5 (all the time). Total scores range from 30 (little or no distortions) to 150 (maximum distortions). Hollon and Kendall (1980) reported both a split-half, odd-even correlation coefficient of 0.97 and an alpha coefficient of 0.96 . The ATQ was employed in the present study to measure cognitive distortions.

\section{Procedure}

A pilot study was conducted prior to the full-scale study to test the appropriateness of the research instruments and to provide information on the kind and amount of resources that would be required for the fullscale study. There were 35 participants involved in the pilot study. The participants were selected from the Greater Accra region. They included males and females within the ages of 18 and 35 years. Participants spent an average of $20 \mathrm{~min}$ to complete each questionnaire. The data for the pilot study was collected within a week. The researchers appreciated the time and effort of the participants after the completion of the questionnaire. Reliability analysis was conducted on the scales and subscales used in the pilot study. The results led the researchers to modify and adapt some scale items.

After the pilot study, the researchers prepared a total of 400 questionnaires and administered them to the participants for the full-scale study. Out of the 400 questionnaires, 374 were retrieved. However, only 362 were complete and therefore considered valid for the analysis. The researchers employed the services of six research assistants who were instrumental in the data collection and data entry. Unemployed youths were accessed at their ideal locations or homes through diligent search. The employed youths were located at their workplaces. The researchers sought the permission of the authorities of the organizations within which the youths were employed. With permission granted, the researchers or their assistants provided the prospective participants with informed consent forms to read and decide whether or not they were willing and ready to participate in the study. Oral explanations and clarifications were also provided about the study. Whilst some participants gave written consents, others gave oral consents. Only those who gave their consents were given the research questionnaires to complete. The researchers allowed ample time for participants to complete the questionnaire. An average time of $20 \mathrm{~min}$ were spent on a questionnaire. The researchers and/or their assistants expressed their gratitude to the participants for their participation in the study. All the completed questionnaires were gathered and analyzed.

\section{Data Analyses}

The Statistical Package for the Social Sciences (SPSS) version 21.0 was used for the data analysis. The analysis was run in two main stages. The first was the preliminary analysis which involved inter-correlation of the study variables. The second involved testing the research hypotheses. The main inferential statistical tests used in this study are the Pearson Product Moment Correlation (Pearson $r$ ) test, the Multivariate Analyses of Variance (MANOVA) test and the Linear Regression test. The Pearson $r$ test was used for inter-correlational analyses among the key variables and the measuring instruments in order to establish their reliability coefficients. Primarily, the Pearson $r$ test was used to compute for the coefficients of internal consistency (Cronbach's $\alpha$ ) to establish the reliability of each of the scales and subscales in the questionnaire. Measures were satisfactory if their alpha reliability values range from 0.70 to 1.00 . This is in accordance with Nunnally's (1978) recommendation that satisfactory coefficient alpha should approximate or be higher than 0.70 if a set of items can constitute a reliable scale.

Two hypotheses were tested. The MANOVA test was used to analyze the first hypotheses. The MANOVA test is most appropriate when comparing mutually exclusive groups on two or more dependent variables measured at least on the interval scale. In the first hypothesis, two mutually exclusive groups were compared on four dependent variables (i.e., depression, cognitive distortions, self-esteem and suicidality) measured on the interval scale. Thus, the MANOVA test became most 
appropriate. The second hypothesis was analyzed with Linear Regression test. The Linear Regression test is the most appropriate test to determine the extent to which certain independent variables predict a dependent variable measured at least on the interval scale. The researchers employed the Regression test to determine the extent to which duration of unemployment predicted depression, cognitive distortions, self-esteem and suicidality among the participants.

\section{Results}

First, the Pearson $r$ inter-correlation analysis was conducted. The key variables of the study were correlated to determine the strength and direction of their relationships. The correlation matrix revealed that all the variables significantly correlated with each other (see Table 1). Duration of unemployment correlated positively with depression $(r=0.26$, $p<0.01)$, cognitive distortions $(r=0.33, p<0.01)$, suicidality $(r=0.29, p<0.01)$ and negatively with selfesteem $(r=-0.24, p<0.01)$.
Using Pillai's trace, there was a significant effect of unemployment on depression, cognitive distortions, self-esteem and suicidal ideation $\left(V=0.04, F_{(4,357)}=\right.$ 3.65, $p<01$, Partial $\eta 2=0.04$ ) (Table 2). Separate univariate ANOVAs on the outcome variables revealed significant effects of unemployment on depression, $\left(F_{(1,360)}=4.60, p<0.05\right.$, Partial $\left.\eta 2=0.01\right)$, cognitive distortions $\left(F_{(1,360)}=11.04, p<0.001\right.$, Partial $\eta 2=0.03)$, self-esteem $\left(F_{(1,360)}=10.09, p<0.01\right.$, Partial $\eta 2=0.03)$ and suicidality $\left(F_{(1,360)}=9.18\right.$, $p<0.05$, Partial $\eta 2=0.03)$. The mean scores show that unemployed youths were more depressed $(\mathrm{M}=51.01$, $\mathrm{SD}=14.30)$ than employed youths $(\mathrm{M}=47.95, \mathrm{SD}=$ 12.65). They were also more cognitively distorted (M $=60.88, \mathrm{SD}=21)$ than employed youths $(\mathrm{M}=54.00$, $\mathrm{SD}=17.84)$, had lower self-esteem $(\mathrm{M}=36.95, \mathrm{SD}=$ 7.39) than employed youths $(\mathrm{M}=39.28)$ and had higher level of suicidality $(\mathrm{M}=11.22, \mathrm{SD}=6.00)$ than employed youths $(\mathrm{M}=9.50, \mathrm{SD}=4.65)$. These results confirm that there is poorer psychological health among unemployed youths than employed youths, thus confirming the first research hypothesis.

Table 1. Correlations among key variables of the study

\begin{tabular}{lllll}
\hline Variables & 1 & 2 & 3 & 4 \\
\hline 1. Unemployment duration & - & & & 5 \\
2. Depression & $0.26^{* *}$ & - & - & - \\
3. Cognitive distortion & $0.33^{* *}$ & $0.63^{* *}$ & $-0.62^{* *}$ & - \\
4. Self-esteem & $-0.24^{* *}$ & $-0.46^{* *}$ & $0.62^{* *}$ & $-0.47^{* *}$ \\
5. Suicidality & $0.29^{* *}$ & $0.68^{* *}$ & & - \\
\hline **
\end{tabular}

Table 2. Effects of youth unemployment on psychological health

\begin{tabular}{lllllllll}
\hline Measure & Employment status & $n$ & Mean & $S D$ & $d f$ & $F$ & Sig. & $\eta 2$ \\
\hline Depression & Employed & 172 & 47.95 & 12.65 & $1 / 360$ & 4.60 & 0.033 & 0.01 \\
& Unemployed & 190 & 51.01 & 14.30 & & & & \\
Cognitive distortions & Employed & 172 & 54.00 & 17.84 & $1 / 360$ & 11.04 & 0.001 & 0.03 \\
& Unemployed & 190 & 60.88 & 21.20 & & & \\
Self-esteem & Employed & 172 & 39.28 & 6.46 & $1 / 360$ & 10.09 & 0.002 & 0.03 \\
& Unemployed & 190 & 36.95 & 7.39 & & & \multirow{2}{*}{0.003} & 0.03 \\
Suicidality & Employed & 172 & 9.50 & 4.65 & $1 / 360$ & 9.18 & 0.003 \\
& Unemployed & 190 & 11.22 & 6.00 & & & & \\
\hline
\end{tabular}

Pillai's Trace: $V=0.04 ; F_{(4,357)}=3.65 ; p=006$, Partial Eta Squared $=0.04$

Table 3. Effect of youth unemployment duration on depression

\begin{tabular}{llll}
\hline Model & $B$ & $S . E$. & $B$ \\
\hline (Constant) & 47.032 & 0.857 & $0.255^{* * *}$ \\
Unemployment duration & 1.614 & 0.323 &
\end{tabular}

Table 4. Effect of youth unemployment duration on cognitive distortions

\begin{tabular}{llll}
\hline Model & $B$ & $S . E$. & $B$ \\
\hline (Constant) & 52.762 & 1.225 & \\
Unemployment duration & 3.098 & 0.461 & $0.334^{* * *}$ \\
\hline
\end{tabular}

$F_{(1,360)}=45.120^{* * *} ; R^{2}=0.111 ;{ }^{* * *} p=0.000$ 
Table 5. Effect of youth unemployment duration on self-esteem

\begin{tabular}{llll}
\hline Model & $B$ & $S . E$. & $B$ \\
\hline (Constant) & 39.285 & 0.446 & $-0.239^{* * *}$ \\
Unemployment duration & -0.784 & 0.168 &
\end{tabular}

Table 6. Effect of youth unemployment duration on suicidality

\begin{tabular}{llll}
\hline Model & $B$ & $S . E$. & $B$ \\
\hline (Constant) & 9.252 & 0.340 & \\
Unemployment duration & 0.736 & 0.128 & $0.290^{* * *}$ \\
\hline$F_{(1,360)}^{*}=32.93^{* * *}, R^{2}=0^{* * * *}$
\end{tabular}

$F_{(1,360)}=32.943^{* * *} ; R^{2}=0.084 ;{ }^{* * *} p=0.000$

The results of the simple linear regression test in Table 3 show a significant regression model with duration of unemployment accounting for $6.5 \%$ variance in depression among the youths $\left(F_{(1,360)}=\right.$ 25.017, $\left.R^{2}=0.065, \quad p<0.001\right)$. Duration of unemployment positively predicted depression among the youths $(\beta=0.255, p<0.001)$.

Table 4 presents summary results of the linear regression test on the effect of duration of unemployment on cognitive distortions among the youths. Per the table, there was a significant regression model with duration of unemployment accounting for $11.1 \%$ variance in cognitive distortions among the youths $\left(F_{(1,360)}=45.120, R^{2}=0.111, p<0.001\right)$. Duration of unemployment positively predicted cognitive distortions among the youths $(\beta=0.334, p<0.001)$.

The linear regression results in Table 5 depict the effect of duration of unemployment on the self-esteem of the youth. The results reveal a significant regression model with duration of unemployment accounting for $5.7 \%$ variance in self-esteem among the youths $\left(F_{(1,360)}=\right.$ 21.827, $\left.R^{2}=0.057, \quad p<0.001\right)$. Duration of unemployment negatively predicted self-esteem among the youths $(\beta=-0.239, p<0.001)$.

Table 6 also displays the linear regression results on the effect of youth unemployment duration on suicidality. The summary results reveal that there was a significant regression model with duration of unemployment accounting for $8.4 \%$ variance in suicidality among the youths $\left(F_{(1,360)}=32.943, R^{2}=\right.$ 0.084, $p<0.001)$. Duration of unemployment positively predicted suicidality among the youths $(\beta=$ $0.290, p<0.001)$.

In sum, duration of youth unemployment positively predicts depression, cognitive distortions and suicidality and negatively predicts self-esteem. In effect, there is confirmation for the second research hypothesis that duration of unemployment will significantly predict poorer psychological health among the youths.

\section{Discussion}

The purpose of the study was to examine the effects of unemployment on the psychological health of youths and to ascertain the impact of duration of youth unemployment on their psychological health. Psychological health was defined in terms of depression, cognitive distortions, self-esteem and suicidality. The first hypothesis predicted that there will be poorer psychological health among unemployed youths than employed youths. Confirmatory evidence was obtained from the data. Consistent with the prediction, there was poorer psychological health among unemployed youths than employed youths. Compared to employed youths, unemployed youths had higher levels of depression, cognitive distortions, suicidality and lower level of selfesteem. This observation confirms the causation hypothesis which predicts negative impact of unemployment on mental health (Schaufeli, 1997). Earlier studies (Feather, 1990; Ezzy, 1993; Winefield, 1995; Winkelman and Winkelman, 1998; Dooley et al., 2000) and recent studies (Breslin and Mustard, 2003; Lorenzini and Giugni, 2010) have shown quite convincingly that unemployment leads to psychological distress and that re-employment improves mental health. This points out a causal relationship between unemployment and poor mental health.

In Ghana, the youth unemployment situation is pathetic. The freeze on employment coupled with the economic crisis makes life unbearable for the youth who are unemployed. Making ends meet becomes nearly impossible for many young men and women who do not have reliable source of support. The economic hardships in the country and the financial constraint of the unemployed youth might largely account for their poor mental health in terms of lower self-esteem and higher levels of depression, cognitive distortions and suicidality. Unemployment is therefore an undesirable situation which needs to be controlled in order to restore good psychological health among the youth. Beyond Ghana, unemployment is known to negatively affect mental health. In its employment outlook, the OECD (2008) observed among five countries that a movement from employment to unemployment had a significant adverse impact on mental health. In Australia, Canada, Switzerland and the U.K., the increase in mental distress was greatest when there was a change from employment 
to inactivity due to illness. However, the small effect size observed in the present study confirms Schaufeli's (1997) observation of a weak relationship between unemployment and psychological distress. In the report of Fryer and Payne (1986) only 10 to $15 \%$ of the variance in distress is explained by employment status. In fact, small effect size was observed on all four dimensions of psychological health (i.e., depression, cognitive distortions, self-esteem and suicidality).

Whilst unemployed youth suffer high levels of depression and lower self-esteem, their cognition may be marred with negative thoughts and distorted view of the self and this could perpetuate their unemployment situation according to the selection hypothesis. In the view of Schaufeli (1997) the fact that unemployment causes psychological distress does not rule out the possibility that high levels of distress could lead to prolonged unemployment. In the view of Joiner et al. (1992), individuals suffering from negative life events often possess negative self-schemas-negative conceptions of their own traits, abilities and behaviour. As a result, such individuals tend to have lower psychological wellbeing. They are usually depressed, anxious and stress. Unemployed youths are likely to adopt negative framework for the interpretation of their circumstance and such interpretation is likely to make them become even more depressed. It is therefore not surprising to witness that unemployed youths had higher depression and cognitive distortions coupled with lower self-esteem.

To a greater extent, the findings of the study provide empirical support to the reformulated learned helplessness theory of depression and the hopelessness theory of depression. The reformulated learned helplessness theory of depression (Abramson et al., 1978; Peterson and Barrett, 1987) explains affective, motivational and cognitive deficits observed in humans following exposure to uncontrollable negative events such as unemployment. The theory predicts that an internal, stable and global attributional tendency, termed a depressogenic attributional style, is a risk factor for the development of a depressive reaction following a negative life event such as chronic illness. Similarly, the hopelessness theory of depression (Abramson et al., 1989) explains the vulnerability of individuals with maladaptive, or negative cognitive styles to depression when they encounter negative life events such as unemployment. Such individuals tend to assign a negative meaning to the negative event they encounter. Those who make such attributions usually expect negative consequences following the occurrence of a negative life event and, as a result, develop a greater risk for depression and suicide (Abramson et al., 1989).

The theoretical explanations point out that once unemployed youths develop distorted views of the self, hopelessness depression becomes inevitable. It is therefore not surprising that a significant positive relationship was found between cognitive distortions and depression in the study. This confirms the theoretical view that the adoption of depressogenic attributional style is likely to lead to lower psychological wellbeing. There is therefore the need to help shape the cognition of unemployed youths to adopt a more positive framework for the assessment of themselves. Negative views of the self will only predict greater levels of depression (Nyarko and Amissah, 2014). It is in this direction that Schaufeli (1997) recommended the adoption of positive attitude and an active way of dealing with unemployment, instead of brooding over one's weakness.

The second hypothesis predicted that duration of unemployment will significantly predict poorer psychological health among the youths. In line with the prediction, it was observed that duration of unemployment significantly predicted poorer psychological health among the youths. Longer duration predicted higher levels of depression, cognitive distortions and suicidality and lower level of self-esteem and vice versa. The second finding shows that the duration of unemployment predicts more psychological distress than the mere form of unemployment. This implies that it is not only unemployment that is worrying but its duration as well. The negative consequences of unemployment increase with the duration of unemployment. As the years run, the economic difficulties of unemployed youths get worse and their psychological problems increase alongside. This is especially true in the Ghanaian context where the national economy is steadily declining with no hope of rescue. The unemployed youths in Ghana therefore have no hope for improvement over their situations. The loss of hope can only predict higher levels of depression, cognitive distortions and suicidality as well as lower levels of self-esteem.

The literature highlights the negative consequences of sustained unemployment. Lorenzini and Giugni (2010) observed among the youths that prolonged unemployment produces financial distress, creates anxiety-related health problems and reduces their overall level of happiness. Again, evidence from OECD (2008) showed that duration of unemployment mattered, though the impact differed across countries. Whilst evidence of a "habituation" effect was found in the U.K., prolonged unemployment led to poorer mental health for males in Australia. In the present study, the "habituation" effect was not the case among unemployed Ghanaian youths. Instead, the Australian observation that long-term unemployment worsened mental health was the case. This confirms the assertion of Winefield and Fryer (1996) that the effect of longterm unemployment is located in specific economies; 
therefore unemployment research must be placed within specific social and cultural context.

Notwithstanding the findings, the study failed to examine the psychological effects of quality employment among the youth. The definition of 'employment status' in the present study was too simplistic and did not reflect the suggestion of Dooley et al. (2000). According to Dooley et al. (2000), it is less useful to simply compare the unemployed with the employed since paid jobs vary qualitatively. In essence, poorer quality jobs have greater propensity to produce mental health problems than better quality jobs. This suggests the need to assess the psychological effects of quality employment together with unemployment. However, this could not be done in the present study due to inappropriate sample compositions for these categories. Whilst the unemployed constituted $52.5 \%(n=190)$ of the total sample of 362 youths, the inadequately employed constituted $26.0 \%(n=94)$ and the adequately employed constituted $21.5 \%(n=78)$ of the sample. Thus, the uneven distribution of adequately employed, inadequately employed and unemployed youths undermined comparative analysis in this regard.

Another limitation emerges from the survey research design employed in the study. Due to the nature of the survey design used in this study, strict causal relationships cannot necessarily be established. In other words, since the survey research design does not allow for the control of extraneous variables as in the case of experiment, the researchers cannot certainly assume that the independent variables solely accounted for the variations in psychological health among the youths. Thus, all inferences or conclusions drawn in this study only depict descriptive relationships but not causal relationship. In this regard, it becomes difficulty to validly prove the causality hypothesis in unemployment research. According to Winefield and Fryer (1996), it is difficult to sort out the impact of unemployment on mental health due to the fact that the cause-and-effect relationship can occur in either direction: Unemployment may impair mental health and mental health problems may reduce a person's chances to become employed. The former is "causative" effect and the latter is "selection" effect. Nevertheless, where longitudinal data are available, it becomes possible to apply statistical methods to sort out the causation. For instance, it is possible to control for the mental health of individuals before job loss in order to assess the impact of job loss on their mental health. The present study could not do so due to the use of the cross-sectional survey design. It only looked at the relationship between unemployment and psychological health at a point in time, which makes the findings difficult to interpret with causal inferences.

\section{Recommendations}

Two sets of recommendations are offered from the study. The first set is practical suggestions meant to curb unemployment in Ghana or, at least, to reduce its psychological effects. The second set is theoretical recommendations to shape the conduct of future research on the psychological effects of youth unemployment.

\section{Recommendations for Practice}

The following recommendations aim at solving the problem of unemployment and improving psychological health among the youths. First, there is the need to make the youths employable by bridging the gap between theory and practice. The onus lies on academic institutions to design and structure their course contents to fit local needs in national context. It is only by this that graduates can acquire and use requisite skills to serve society through innovations and self-creation of opportunities. Academic institutions should also place more emphasis on practical training, especially with industrial attachment, to expose graduates to adequate practical work to provide them with work experience prior to the completion of their academic programme. In addition, course structure should be reviewed regularly in line with demands of industry and the country's development goals. There is also the need for proactive interventions or measures that seek to create more job opportunities for the youth. Government should encourage private sector partnership in job creation. This can be a good step in creating more job opportunities to absorb the army of graduates in search for non-existing jobs in the country. This however can best be described as an immediate intervention or measure with short-term effect.

Since agriculture remains the backbone of the economy, government ought to come out with policies and incentives that will attract the youths in the agricultural industry. Students should be re-oriented to see all jobs as important so as to strive to make the best out of them. Particularly, agriculture can be made a core course for both basic and secondary education. In this way, most citizens will be able to grasp the basic skills and technologies useful in boosting agricultural production. Moreover, local industries need to be promoted to absorb most of the unemployed youths in the local communities. As Amankrah (2000a; 2000b) suggested, there is the need to formalize and promote district-level community-based apprenticeship training schemes, with the support of the Government, to take care of the youths who have dropped out of school or who have never been to school. Technical and vocational institutes need to be equipped for apprenticeship in both the formal and informal industries. In addition, there is also the need to make apprenticeship and trade more attractive to the youths through registration of 
apprenticeship providers, standardization of content, specification of training duration and certification in conformity with industry and identifiable trade associations. This, no doubt, will be a significant boost to the local industry, expand the production and employment base of the economy and, in the long run, increase national productivity.

Finally, based on the first research finding that unemployed youths experience poorer psychological health than employed youths, there is the need to extend clinical services to unemployed youths. Unemployed youths are known to suffer lower self-esteem and higher depression, cognitive distortions and suicidality. The significant association among these mental health variables makes it critical to provide accessible and timely clinical interventional services to the unemployed. The researchers propose the use of cognitive-behaviour therapy as an effective treatment option to shape the cognition of unemployed youths and to make them become less depressed. There is the need for clinical psychologists to help the unemployed to replace their distorted thoughts with more rational and logical thoughts in order to maximize their psychological health. They need to develop positive views of themselves and trust in their potentials. Particularly, unemployed youths with higher suicidal tendencies need to be identified and assisted to prevent future calamities.

\section{Recommendations for Future Research}

On the bases of the findings and the identified limitation of this study, the following recommendations are made for future research consideration. First, based on the direction provided by Dooley et al. (2000), it is necessary for future researchers to assess the psychological effects of quality employment by comparing the unemployed, the inadequately employed and the adequately employed youths on psychological health. Adequately employed individuals should comprise youths whose jobs and salaries commensurate with their qualifications and who are satisfied with their jobs. Inadequately employed individuals should comprise youths whose jobs and salaries do not commensurate their qualifications. Such individuals are dissatisfied with their jobs and may be seeking alternative jobs where they can find satisfaction.

Similarly, in order to clearly determine the effect size of youth unemployment, there is the need to distinguish two categories of unemployment-'never employed before' and 'previously employed.' The former refers to individuals who have never had any chance to work for salary or who have never been engaged in a job that provides regular income. The latter refers to individuals who were previously employed but have lost their jobs. This is necessary because previous jobs could provide certain accumulated benefits for the unemployed and this is likely to obscure the psychological effects of youth unemployment.

\section{Conclusion}

The study has revealed the deleterious effects of unemployment on psychological health among the youths in Ghana. Consistent with expectation, it was observed that unemployed youths in Ghana had poorer psychological health than employed youths. Specifically, unemployed youths were found more depressed, more cognitively distorted, more suicidal and had lower selfesteem compared to their employed counterparts. Additionally, duration of unemployment predicted poorer psychological health among the youths. Longer duration predicted higher levels of depression, cognitive distortions and suicidality as well as lower level of self-esteem. These observations suggest that unemployment, in itself, devastates the mental life of young people in a society. Moreover, as unemployment continuously lingers, its devastating effects on mental health are also sustained and even worsen. This means that young people do not habituate the negative psychological consequences of unemployment with time. Instead, they live it in an increasingly disruptive and destructive manner. Given the negative psychological consequences of youth unemployment in Ghana, there is a need for the government of Ghana to plan and implement pragmatic youth programmes that will contain Ghanaian youths in search for job.

\section{Acknowledgement}

The authors acknowledge the immense support of their research assistants-Joshua Adjei, Nelly Betty Fosu, James Kwame Peprah, Benedicta Addae, Shadrach Addae and Florence Awurama Dogbo. The authors also acknowledge the time and effort of their research participants.

\section{Funding Information}

The authors self-funded all activities of this research.

\section{Author's Contributions}

Christopher Martin Amissah: Conceived the study. Christopher Martin Amissah and Kingsley Nyarko: Co-operatively designed and executed the study.

\section{Ethics}

The study strictly adhered to ethical principles governing research with human participants. There is complete anonymity and confidentiality for research participants. Only group scores have been reported with no references to individual participants in the 
study. The data is original. All cited studies are duly acknowledged.

\section{References}

Abramson, L.Y., G.I. Metalsky and L.B. Alloy, 1989. Hopelessness depression: A theory-based subtype of depression. Psychol. Rev., 96: 358-372. DOI: 10.1037/0033-295X.96.2.358

Abramson, L.Y., M.E.P. Seligman and J.D. Teasdale, 1978. Learned helplessness in humans: Critique and reformulation. J. Abnormal Psychol., 87: 49-74. DOI: $10.1037 / 0021-843 X .87 .1 .49$

Adinkrah, M., 2014. Confessions: Suicidal ideation on a Ghanaian radio program. J. Public Health Epidemiol., 6: 229-234. DOI: $10.5897 /$ JPHE2013.0603

Alloy, L.B., L.Y. Abramson, S.M. Safford and B.E. Gibb, 2006. The Cognitive Vulnerability to Depression (CVD) Project: Current Findings and Future Directions. In: Cognitive Vulnerability to Emotional Disorders, Alloy, L.B. and J.H. Riskind (Eds.), Lawrence Erlbaum Associates Publishers, Mahwah, NJ US., pp: 33-61.

Alloy, L.B., L.Y. Abramson, M.E. Hogan, W.G. Whitehouse and D.T. Rose et al., 2000. The temple-Wisconsin cognitive vulnerability to depression project: Lifetime history of Axis I psychopathology in individuals at high and low cognitive risk for depression. J. Abnormal Psychol., 109: 403-418.

DOI: 10.1037/0021-843X.109.3.403

Amankrah, J.Y., 2000a. Policy Focus for Improving the Productivity of the Informal Sector in Ghana. Report prepared for NACVET as background paper towards the development of a national policy for Vocational and Technical Education in Ghana.

Amankrah, J.Y., 2000b. Improving productivity in the informal sector in Ghana: Policy issues and strategies for training in the informal sector. Report prepared for the World Bank

Amankrah, J.Y., 2005. Ghana decent work statistical indicators: Fact finding study. ILO Working Paper, ILO, Geneva.

Breslin, F.C. and C. Mustard, 2003. Factors influencing the impact of unemployment on mental health among young and older adults in a longitudinal, population-based survey. Scandinavian J. Work Environ. Health, 29: 5-14. DOI: $10.5271 /$ sjweh. 698

Carmichael, F. and R. Ward, 2001. Male unemployment and crime in England and Wales. Econom. Lett., 5: 111-115. DOI: $10.1016 / \mathrm{S} 0165-1765(01) 00466-9$
Chang, E.C., L.J. Sanna, J.K. Hirsch and E.L. Jeglic, 2010. Loneliness and negative life events as predictors of hopelessness and suicidal behaviors in Hispanics: Evidence for a Diathesis-Stress Model. J. Clin. Psychol., 66: 1242-1253.

DOI: $10.1002 /$ jclp. 20721

Clark, A.E. and A.J. Oswald, 1994. Unhappiness and unemployment. Economic J., 104: 648-659. DOI: $10.2307 / 2234639$

Cohen, F., M.E. Kemeny, L.S. Zegans, P. Johnson and K.A. Kearney et al., 2007. Immune function declines with unemployment and recovers after stressor termination. Psychosomatic Med., 69: 225-234. DOI: 10.1097/PSY.0b013e31803139a6

Córdoba-Doña, J.A., M.S. Sebastián, A. Escolar-Pujolar, J.E. Martínez-Faure and P.E. Gustafsson, 2014. Economic crisis and suicidal behaviour: The role of unemployment, sex and age in Andalusia, Southern Spain. Int. J. Equity Health, 13: 55-61. DOI: $10.1186 / 1475-9276-13-55$

Dooley, D., J. Prause and K.A. Ham-Rowbottom, 2000. Underemployment and depression: Longitudinal relationships. J. Health Soc. Behav., 41: 421-436. DOI: $10.2307 / 2676295$

Erikson, E.H., 1968. Identify: Youth and crisis. Faber and Faber, London.

Ezzy, D., 1993. Unemployment and mental health: A critical review. Soc. Sci. Med., 37: 41-52. DOI: 10.1016/0277-9536(93)90316-V

Fajana, S., 2000. Functioning of the Nigerian Labour Market. 1st Edn., Labonfin and Company, Lagos, ISBN-10: 9783484354, pp: 450.

Feather, N.T., 1990. The Psychological Impact of Unemployment. 1st Edn., Springer, New York, ISBN-10: 0387970274, pp: 285.

Fergusson, D.M., J.M. Boden and L.J. Horwood, 2007. Unemployment and suicidal behavior in a New Zealand birth cohort: A fixed effects regression analysis. CRISIS, 28: 95-101.

DOI: $10.1027 / 0227-5910.28 .2 .95$

Fryer, D. and R.L. Payne, 1986. Being Unemployed: A Review on the Literature on the Psychological Experience of Unemployment. In: International Review of Industrial and Organizational Psychology, Cooper, C.L. and I. Robinson (Eds.), Wiley, New York.

GSS, 2012. Population and housing census: Summary report of final results. Ghana Statistical Service, Accra.

Hollon, S.D. and P.C. Kendall, 1980. Cognitive selfstatements in depression: Development of an Automatic Thoughts Questionnaire. Cognitive Therapy Res., 4: 383-395. DOI: $10.1007 / \mathrm{BF} 01178214$ 
ISSER, 2007. Registered unemployment in Ghana. Institute of Statistical, Social and Economic Research, University of Ghana Press, Accra.

ILO, 2005. Youth: Pathways to decent work. Promoting youth employment-Tackling the challenge. International Labour Organization, Geneva.

ILO, 1982. Thirteenth international conference of labour statisticians: Resolution concerning statistics of the economically active population, employment, unemployment and underemployment. Current international recommendations on labour statistics, ILO, Geneva.

Jahoda, M., 1979. The impact of unemployment in the 1930s and 1970s'. Bull. British Psychol. Society, 32: $309-314$.

Jahoda, M., 1981. Work, employment and unemployment: Values, theories and approaches in social research. Am. Psychol., 36: 184-191. DOI: 10.1037/0003-066X.36.2.184

Jahoda, M., 1982. Employment and Unemployment. 1st Edn., Cambridge University Press, Cambridge. MA.

Jahoda, M., P.F. Lazarsfeld and H. Zeisel, 1933. Marienthal: The sociography of an unemployed community. Aldine, Chicago.

Joiner, Jr., T.E., M.S. Alfano and G.I. Metalsky, 1992. When depression breeds contempt: Reassurance seeking, self-esteem and rejection of depressed college students by their roommates. J. Abnormal Psychol., 101: 165-173.

DOI: 10.1037/0021-843X.101.1.165

Knizek, B.L., C.S. Akotia and H. Hjelmeland, 2010. A qualitative study of attitudes toward suicide and suicide prevention among psychology students in Ghana. OMEGA, 62: 169-186.

DOI: $10.2190 /$ OM.62.2.e

Lorenzini, J. and M. Giugni, 2010. Youth coping with unemployment: The role of social support. Proceedings of the YOUNEX Swiss Workshop on "Youth, Unemployment, Precariousness and Exclusion in Switzerland", (PES' 10), Geneva.

McKee-Ryan, F.M., Z. Song, C.R. Wamberg and A.J. Kinicki, 2005. Psychological and physical wellbeing during unemployment: A meta-analytic study. J. Applied Psychol., 90: 53-76.

DOI: $10.1037 / 0021-9010.90 .1 .53$

Metalsky, G.I. and T.E. Joiner Jr., 1997. The hopelessness depression symptom questionnaire. Cognitive Therapy Res., 21: 359-384.

DOI: $10.1023 / \mathrm{A}: 1021882717784$

Metalsky, G.I., T.E. Joiner Jr., T.S. Hardin and L.Y. Abramson, 1993. Depressive reactions to failure in a naturalistic setting: A test of the hopelessness and self-esteem theories of depression. J. Abnormal Psychol., 102: 101-109.

DOI: $10.1037 / 0021-843 X .102 .1 .101$
Murphy, G.C. and J.A. Athanasou, 1999. The effect of unemployment on mental health. J. Occupat. Organiz. Psychol., 72: 83-99.

DOI: $10.1348 / 096317999166518$

Nunnally, J.C., 1978. Psychometric Theory. 2nd Edn., McGraw-Hill, New York, ISBN-10: 0070474656, pp: 701.

Nyarko, K. and C.M. Amissah, 2014. Cognitive distortions and depression among undergraduate students. Res. Humanit. Soc. Sci., 4: 69-75.

OECD, 2008. Are all jobs good for your health? The impact of work status and working conditions on mental health. OECD Employment Outlook.

Osafo, J., H. Hjelmeland, C.S. Akotia and B.L. Knizek, 2011. Social injury: An interpretative phenomenological analysis of the attitudes towards suicide of lay persons in Ghana. Int. J. Qualitative Study Health Well-be., 6: 8708-8708.

DOI: $10.3402 / q h w . v 6 i 4.8708$

Osman, A., C.L. Bagge, P.M. Gutierrez, L.C. Konick and B.A. Kopper et al., 2001. The Suicidal Behaviors Questionnaire-Revised (SBQ-R): Validation with clinical and nonclinical samples. Assessment, 8: 443-454. DOI: 10.1177/107319110100800409

Paugam, S., 2004. Laprécarité Professionnelle: Effets Individuels et Sociaux. In: Entretiendu CRIEVAT Laval, Fournier, G. and B. Bourassa (Eds.), Pressesdel' Université Laval, Québec.

Paul, K.I., 2005. The negative mental health effect of unemployment: Meta-analyses of cross-sectional and longitudinal data. $\mathrm{PhD}$ Thesis, University of Erlangen-Nürnberg.

Paul, K.I. and K. Moser, 2009. Unemployment impairs mental health: Meta-analyses. J. Vocat. Behav., 74: 264-282. DOI: 10.1016/j.jvb.2009.01.001

Peña, J.B., P.A. Wyman, C.H. Brown, M.M. Matthieu and T.E. Olivares et al., 2008. Immigration generation status and its association with suicide attempts, substance use and depressive symptoms among Latino adolescents in the USA. Prevent. Sci., 9: 299-310.

DOI: $10.1007 / \mathrm{s} 11121-008-0105-\mathrm{x}$

Peterson, C. and M.E.P. Seligman, 1984. Causal explanations as a risk factor for depression: Theory and evidence. Psychol. Rev., 91: 347-374.

DOI: 10.1037/0033-295X.91.3.347

Peterson, C. and M.E.P. Seligman, 1987. Explanatory style and illness. J. Personality, 55: 237-265. DOI: 10.1111/j.1467-6494.1987.tb00436.x

Pharr, J.R., S. Moonie and T.J. Bungum, 2012. The Impact of unemployment on mental and physical health, access to health care and health risk behaviors. ISRN Public Health, 2012: 483432-483438. DOI: 10.5402/2012/483432 
Punch, K.F., 2005. Introduction to Social Research: Quantitative and Qualitative Approaches. 2nd Edn., SAGE Publications, London, ISBN-10: 0761944176, pp: 320.

Reine, I., M. Novo and A. Hammarstrom, 2013. Unemployment and ill health-a gender analysis: Results from a 14-year follow-up of the Northern Swedish Cohort. Public Health, 127: 214-222. DOI: $10.1016 /$ j.puhe.2012.12.005

Rew, L., N. Thomas, S.D. Horner, M.D. Resnick and T. Beuhring, 2001. Correlates of recent suicide attempts in a triethnic group of adolescents. J. Nurs. Scholarship, 33: 361-367. DOI: $10.1111 /$ j.1547-5069.2001.00361.x

Roberts, J.E. and S.M. Monroe, 1992. Vulnerable selfesteem and depressive symptoms: Prospective findings comparing three alternative conceptualizations. J. Personality Soc. Psychol., 62: 804-812. DOI: 10.1037/0022-3514.62.5.804

Rosenberg, M., 1965. Society and the Adolescent SelfImage. 1st Edn., Princeton University Press, Princeton, NJ., ISBN-10: 0691028052, pp: 326.

Russell, H., 1999. Friends in low places: Gender, unemployment and sociability. Work Employment Society, 13: 205-224. DOI: $10.1177 / 09500179922117917$

Schaufeli, W.B., 1997. Youth unemployment and mental health: Some Dutch findings. J. Adolescence, 20: 281-292. DOI: 10.1006/jado.1997.0085

Seligman, M.E.P., 1975. Helplessness: On depression, development and death. W.H. Freeman, San Francisco.

Sommers, M., 2003. Urbanization, war and Africa's youth at risk: Towards understanding and addressing future challenges. United States Agency for International Development, Washington, D.C.
Wadsworth, T. and C.E. Kubrin, 2007. Hispanic suicide in U.S. metropolitan areas: Examining the effects of immigration, assimilation, affluence and disadvantage. Am. J. Sociol., 112: 1848-1885. DOI: $10.1086 / 512711$

Winefield, A.H., 1995. Unemployment: Its Psychological Costs. In: International Review of Industrial and Organizational Psychology, Cooper, C.L. and I.T. Robertson (Eds.), Wiley, London, pp: 169-212.

Winefield, A.H. and D. Fryer, 1996. Some emerging threats to the validity of research on unemployment and mental health. Austral. J. Soc. Res., 2: 115-128.

Winefield, A.H. and M. Tiggemann, 1985. Psychological correlates of employment and unemployment: Effects, predisposing factors and sex differences. J. Occupat. Psychol., 58: 229-242. DOI: $10.1111 /$ j.2044-8325.1985.tb00198.x

Winkelman, L. and R. Winkelman, 1998. Why are the unemployed so unhappy? Evidence from panel data. Economica, 65: 1-15. DOI: $10.1111 / 1468-0335.00111$

WHO, 2000. Preventing suicide: A resource for general physicians' mental and behavioural disorders. Department of Mental Health: World Health Organization, WHO worldwide initiative for the prevention of suicide, Geneva.

Yarquah, J.A. and S. Baafi-Frimpong, 2012. Social cost of educated youth unemployment in Ghana and its implications for education. Centrepoint Humanit. Edit., 14: 122-143. 